[IN PRESS IN SOCIAL PSYCHOLOGICAL AND PERSONALITY SCIENCE] [DOI: $10.1177 / 1948550619866187]$

Mate preferences in three Muslim-majority countries: Sex differences and personality correlates

Mohammad Atari

Department of Psychology, University of Southern California, CA, USA

Nabiha Chaudhary

Department of Psychology, University of Cincinnati, OH, USA

Laith Al-Shawaf

Department of Psychology, University of Colorado, Colorado Springs, CO, USA

Corresponding Author: Mohammad Atari, Department of Psychology, University of Southern California, SGM 501, 3620 McClintock Ave, Los Angeles, CA 90089, Email: Atari@USC.edu 


\title{
Mate preferences in three Muslim-majority countries: Sex differences and personality correlates
}

\begin{abstract}
Cross-cultural research on long-term mate preferences in Muslim-majority countries is scarce. The research described here aims to examine the KASER model of mate preferences (Kindness/Dependability, Attractiveness/Sexuality, Status/Resources, Education/Intelligence, and Religiosity/Chastity [KASER]) in Iran, Pakistan and Turkey $(N=1,089)$. We examined structural validity, measurement invariance between men and women, sex differences, cultural differences, and Big Five personality correlates of these dimensions of mate preferences. Findings supported pre-registered hypotheses regarding sex differences in mate preferences. Multi-level models suggested that the magnitude of sex differences was invariant across cultures. Personality correlates of mate preferences varied across cultures, but Agreeableness consistently predicted the preference for kind and dependable partners across cultures. In sum, sex differences in mate preferences within and across three Muslim-majority countries described here replicate previous findings, but evidence for personality correlates of mate preferences is mixed, variable across cultures, and in need of further examination in non-Western samples. Keywords: mate preferences, sex differences, Big Five, personality, cross-cultural psychology. WORD COUNT $=4,702$ words
\end{abstract}




\section{Introduction}

Selecting a long-term romantic partner is a key life decision and influences most aspects of our lives. Mate choice is associated with physical well-being, mental health, economic decision-making, workplace behavior, social interactions (see Diener \& Seligman, 2002; Hill \& Buss, 2006), and brain structure (Kawamichi et al., 2016). Previous research has identified some well-established sex differences in men and women's mate preferences (Buss, 1989; Buss \& Schmitt, 1993; Schmitt, 2005). The processes underlying human mate choice and people's preferences in choosing a long-term romantic partner are complex (Conroy-Beam \& Buss, 2016). Although most of the literature on human mating psychology relies heavily on Western, Educated, Industrialized, Rich, and Democratic societies (WEIRD; Henrich, Heine, \& Norenzayan, 2010), psychologists have recently begun to explore mating psychology in Middle Eastern Muslim-majority countries (e.g., Chaudhary, Al-Shawaf, \& Buss, 2018; Chegeni, Pirkalani, \& Dehshiri, 2018). Using a recently developed multi-dimensional model of long-term mate preferences in Iran (Atari, 2017), we present, and make publicly available, data from three Muslim-majority countries (Pakistan, Iran, and Turkey), examine pre-registered hypotheses about sex differences in mate preferences in these cultures, and investigate Big Five predictors of mate preferences in each culture.

\section{Sex Differences in Mate Preferences}

There are some universal preferences in mate selection. For example, people tend to prefer kind, healthy, and empathetic partners and dislike cruel partners or those suffering from a terminal illness (e.g., Boysen, 2017). Several reasons might underlie these preferences. For example, kind and empathetic partners are more likely to cooperate in the maintenance of a longterm relationship (Buss \& Barnes, 1986), increase relationship satisfaction (Valentine, Li, 
Meltzer, \&Tsai, 2019), and are more likely to be caring parents in the future (Buckels et al., 2015). There is a substantial body of evidence from different researchers, cultures, and methods showing that men and women differ in their long-term mate preferences (see Bech-Sørensen \& Pollet, 2016; Buss, 1989; Eastwick \& Finkel, 2008). Compared with women, men tend to be more attracted to indicators of fertility and reproductive value, including physical attractiveness and youth (Meltzer, McNulty, Jackson, \& Karney, 2014; Sugiyama, 2005). Compared with men, women report stronger preferences for signs of the ability to acquire resources, social status, and dominance (Li, Bailey, Kenrick, \& Linsenmeier, 2002). Across cultures, women rate indicators of access to resources (e.g., wealth, achievement) and willingness to invest (e.g., love, commitment) as particularly desirable in a long-term romantic partner (Buss 1989; Shackelford, Schmitt, \& Buss, 2005). These findings are universal, but the magnitude of the sex difference varies from culture to culture (see Buss, 1989). A recent analysis showed that sex differences in preferences for "good earning capacity" may be slightly smaller in countries with greater gender equality such as Sweden or Norway (e.g., Zhang, Lee, DeBruine, \& Jones, 2019).

Sex differences in mate preferences have been found to be relatively invariant over time in different cultures. Kamble, Shackelford, Pham, and Buss (2014) used two research instruments to examine sex differences in mate preferences in India and compare the findings with Indian mate preferences reported in Buss (1989). Mate preferences for "mutual attraction" and "love" remained important for Indian men and women, being invariant over a quarter of a century, despite India's history of arranged marriage. Sex differences in mate preferences for physical attractiveness and resources (e.g., good financial prospects, social status) remained relatively invariant over time: Women placed greater emphasis on financial prospects than did men; and men placed greater emphasis on physical attractiveness. Souza, Conroy-Beam, and 
Buss (2016) compared a large sample of modern Brazilians with a Brazilian sample studied in Buss (1989). Mate preferences for "mutual attraction" and "kindness", and "intelligence" remained important for both sexes and sex differences in these preferences remained relatively invariant over time. Sex differences in preferences for cues to fertility (e.g., youth, physical attractiveness) and resources (earning capacity, financial prospects, social status) also remained relatively invariant over time and replicated previous findings. These findings point to the stability of sex differences in mate preferences. However, much less is known about these sex differences in mate preferences in Muslim-majority countries.

Building upon findings of Atari and Jamali (2016) in Iran, Atari (2017) developed a fivefactor model of mate preferences using a factor analytic approach. This model consists of five dimensions in choosing a long-term mate: Kindness/dependability, Attractiveness/sexuality, Status/resources, Education/intelligence, and Religiosity/chastity (KASER; Atari, 2017). In terms of sex differences, women tended to place more value on Kindness/dependability (Cohen's $d=0.48)$, Status/resources (Cohen's $d=1.30)$, and Education/intelligence (Cohen's $d=0.66$ ) than did men. On the other hand, men placed more emphasis on Attractiveness/sexuality (Cohen's $d=-0.47$ ) than did women in long-term mating. No significant sex difference emerged for Religiosity/chastity (Cohen's $d=-0.13$ ). This multi-dimensional model of long-term mate preferences has been used in Iran (e.g., Atari, Chegeni, \& Fathi, 2017), but no other Middle Eastern countries.

\section{Personality and Mate Preferences}

Empirical studies have found that personality predicts mate preferences. Recently, Gebauer et al. (2012) examined the relationship between Big Two personality traits (agency/competence and communion/warmth; Abele, Cuddy, Judd, \& Yzerbyt, 2008) and Big 
Three mate preferences (attractiveness, status, and warmth; Fletcher, Simpson, Thomas, \& Giles, 1999). These authors provided supporting evidence for the similarity-attracts hypothesis in a cross-cultural sample; however, they also found that culture may moderate these relationships. For example, agentic individuals (more than communal individuals) preferred attractiveness in mate selection, but this association was not significant in attractiveness-valuing countries (e.g., Austria, Italy). One broader implication might be that characteristics that are already preferred in a society are less heavily influenced by an individual's personality traits. In other words, when a mate preference is normative in a culture, personality traits are not powerful predictors of that preference in that culture. Gebauer and colleagues' (2012) findings showed that robust differences exist between cultures in the strength of similarity hypothesis effects (i.e., individuals ending up with mates who are similar to themselves; see Buss, 1984) at least in the domain of Big Two personality traits. More specifically, the "similarity-attracts" hypothesis, in the domain of physical attractiveness, holds in countries where attractiveness preferences are not normative in selecting a long-term mate (e.g., France, Poland). The similarity hypothesis, also known as assortative mating, refers to individuals' propensity to mate with partners with similar traits more frequently than would be expected under a random mating pattern.

Most cross-cultural studies in the literature have relied on WEIRD countries. To our knowledge, no cross-cultural study has investigated personality and mate preferences in religious Muslim countries. The few studies in non-WEIRD, Muslim-majority countries focused exclusively on limited samples (e.g., Atari \& Chegeni, 2017; Chaudhary et al., 2018) and do not reveal anything about the relationship between basic personality traits (i.e., the Big Five) and long-term mate preferences in such cultural settings. Therefore, it is important to further examine 
the links between different personality traits and mate preferences in different cultures, particularly non-WEIRD ones (Štěrbová et al., 2017).

\section{The Current Research}

In order to fill this gap and extend recent cross-cultural work on mate preferences, we designed the current research to investigate (1) sex differences in long-term mate preferences using a multi-dimensional model developed in non-Western cultures; (2) measurement invariance (i.e., a statistical test to examine whether a given measure is interpreted in a conceptually similar manner by respondents representing different groups or cultural backgrounds) of long-term mate preferences using a novel measure of mate preferences in three languages (Turkish, Farsi, and Urdu); (3) links between the Big Five model of personality and the KASER model of mate preferences in Turkey, Iran, and Pakistan. According to the aforementioned literature on mate preferences in different cultures (see Atari, 2017; Buss, 1989; Zhang et al., 2019), we pre-registered our hypotheses, which were as follows: (H1) Men would score higher than women on the preference for attractiveness/sexuality factor; $(H 2)$ Women would score higher than men on the preference for status/resources factor; (H3) Women would score higher than men on the preference for kindness/dependability factor; $(H 4)$ Women would score higher than men on the preference for education/intelligence factor. Based on assortative mating literature and previous findings (see Atari \& Chegeni, 2017; Buss, 1984; Lewis, AlShawaf, \& Yilmaz, 2015; Štěrbová et al., 2017), we hypothesized that Openness to Experience would be negatively associated with the preference for religiosity/Chastity (H5). We predicted that Agreeableness would be positively associated with kindness/dependability $(H 6 a)$ and religiosity/chastity $(H 6 b)$; Conscientiousness would be positively associated with 
kindness/dependability $(H 7 a)$ and religiosity/chastity $(H 7 b)$. All pre-registered hypotheses are summarized in Table 1.

Table 1

Summary of All Pre-Registered Hypotheses

\begin{tabular}{|c|c|c|}
\hline No. & Hypothesis & Result \\
\hline 1 & $\begin{array}{l}\text { Men will score higher than women on the preference for } \\
\text { Attractiveness/sexuality }\end{array}$ & Supported in Iran and Turkey \\
\hline 2 & $\begin{array}{l}\text { Women will score higher than men on the preference for } \\
\text { Status/resources }\end{array}$ & Supported in all three countries \\
\hline 3 & $\begin{array}{l}\text { Women will score higher than men on the preference for } \\
\text { Kindness/dependability }\end{array}$ & Supported in all three countries \\
\hline 4 & $\begin{array}{l}\text { Women will score higher than men on the preference for } \\
\text { Education/intelligence }\end{array}$ & Supported in Iran and Turkey \\
\hline 5 & $\begin{array}{l}\text { Openness to Experience will be negatively associated } \\
\text { with the preference for Religiosity/chastity }\end{array}$ & Supported in Iran and Turkey \\
\hline $6 \mathrm{~A}$ & $\begin{array}{l}\text { Agreeableness will be positively associated with the } \\
\text { preference for Kindness/dependability }\end{array}$ & Supported in all three countries \\
\hline $6 \mathrm{~B}$ & $\begin{array}{l}\text { Agreeableness will be positively associated with the } \\
\text { preference for Religiosity/chastity }\end{array}$ & Not supported \\
\hline $7 \mathrm{~A}$ & $\begin{array}{l}\text { Conscientiousness will be positively associated with the } \\
\text { preference for Kindness/dependability }\end{array}$ & Supported in Iran \\
\hline $7 \mathrm{~B}$ & $\begin{array}{l}\text { Conscientiousness will be positively associated with the } \\
\text { preference for Religiosity/chastity }\end{array}$ & Supported in Iran \\
\hline
\end{tabular}

\section{Methods}




\section{Participants}

We recruited 1,089 heterosexual participants from Pakistan ( $n=325 ; 166$ women), Iran ( $n=251 ; 138$ women), and Turkey ( $n=513 ; 306$ women). The data in Pakistan were collected from three universities, the data in Iran were collected from public places (including universities), and in Turkey we used an online setting to collect data from university students. The mean self-reported ages were $22.78($ range $=15-37, M d=22, S D=3.01), 24.51($ range $=17$ $46, M d=24, S D=5.56)$, and $25.12($ range $=15-76, M d=22, S D=8.01)$ years in Pakistan, Iran, and Turkey, respectively. All participants identified themselves as Pakistani, Iranian, and Turkish nationals and spoke Urdu, Farsi, and Turkish as their first language. After agreeing to participate in this study, each participant completed a set of self-report measures.

\section{Measures}

Mate preferences. We used the Iranian Mate Preferences Scale-20 (IMPS-20; Atari, 2017) which is a short operationalization of the KASER model of long-term mate preferences. This measure was originally validated in Farsi, so we created the Urdu and Turkish versions using a standard back-translation technique (Brislin, 1970) before data collection. Specifically, translators fluent in Urdu and Turkish (and English) translated the items into the local language from the original version, then two independent translators unaffiliated with this study translated the items back into English. Small differences that emerged during the translation process were resolved between the translators, the scale developer, and the authors, resulting in Urdu (Urdu Mate Preferences Scale; UMPS) and Turkish (Turkish Mate Preferences Scale; TMPS) versions

of the scale. This measure has 20 sex-neutral items categorized under five factors. Each item is a characteristic that individuals rate when choosing a long-term romantic partner on a 4-point scale ranging from 1 (Unimportant) to 4 (Very important). Kindness/dependability (K), 
Attractiveness/sexuality (A), Status/resources (S), Education/intelligence (E), and

Religiosity/chastity (R) are measured by 7, 3, 3, 3, and 4 items, respectively. Internal consistency coefficients for all factors are summarized in Table 2 .

The Big Five. We used a short measure of the Big Five dimensions of personality. All participants completed the Ten-Item Personality Inventory (TIPI; Gosling, Rentfrow, \& Swann, 2003). Each personality dimension is measured using two items, one of which needs reverse scoring. All items are rated along a scale ranging from 1 (Strongly disagree) to 7 (Strongly agree). The Farsi, Urdu, and Turkish translations of the TIPI have been used in recent studies with desirable results (Afahmi, Mohammadi-Zarghan, \& Atari, 2017; Atak, 2013; Khan, Ahmed, \& Abid, 2016). Although the number of items in the TIPI (2 items per trait, see Cortina, 1993) make the coefficient alpha an inadequate method for evaluation of TIPI's reliability, we report all alpha coefficients in Table 2.

Table 2

Descriptive Statistics and Internal Reliability Coefficients of the Study Variables

\begin{tabular}{lcccccccccc}
\hline Variable & \multicolumn{3}{c}{ Iran } & \multicolumn{3}{c}{ Pakistan } & \multicolumn{3}{c}{ Turkey } \\
& \multicolumn{1}{c}{$M$} & $S D$ & $\alpha$ & $M$ & $S D$ & $\alpha$ & $M$ & $S D$ & $\alpha$ \\
& & & & & & & & & \\
& & & & & & & & \\
& & & & & & & & \\
Kindness/dependability & 3.80 & 0.30 & .79 & 3.24 & 0.48 & .72 & 3.37 & 0.41 & .69 \\
Attractiveness/sexuality & 3.10 & 0.68 & .77 & 3.02 & 0.58 & .51 & 2.58 & 0.63 & .76 \\
Status/resources & 2.86 & 0.81 & .77 & 2.92 & 0.76 & .79 & 2.00 & 0.73 & .84 \\
Education/intelligence & 3.11 & 0.71 & .71 & 3.08 & 0.69 & .70 & 2.90 & 0.73 & .66 \\
Religiosity/chastity & 2.75 & 0.79 & .71 & 3.25 & 0.53 & .55 & 1.74 & 0.76 & .77 \\
Extraversion & 8.75 & 3.15 & .53 & 8.56 & 2.38 & $-.02 *$ & 8.43 & 2.78 & .10 \\
Agreeableness & 9.22 & 2.24 & .20 & 8.78 & 2.00 & $-.33 *$ & 8.61 & 2.43 & .10 \\
Conscientiousness & 10.57 & 2.74 & .50 & 9.14 & 2.29 & .09 & 9.29 & 2.68 & .14 \\
\hline
\end{tabular}




\begin{tabular}{lccccccccc}
\hline Emotional Stability & 7.81 & 3.04 & .36 & 8.22 & 2.17 & $-.21^{*}$ & 7.97 & 2.49 & $-.06^{*}$ \\
Openness to Experience & 10.88 & 2.46 & .35 & 8.86 & 2.03 & $-.28^{*}$ & 8.94 & 2.91 & .01
\end{tabular}

*these subscales showed negative inter-item correlations in TIPI's 2-item subscales.

\section{Data analysis}

Data from three countries were screened for skewness and kurtosis (Kline, 2010).

Demographic variables were examined using standard descriptive statistics within each sample, including means $(M)$, standard deviations $(S D)$, and internal consistencies (Cronbach's $\alpha$ ) using psych 1.8 (Revelle, 2017) in $R$ programming language (version 3.4.2; R Core Team, 2017). The main analysis was conducted in three steps. First, single-group confirmatory factor analyses (CFAs) examined each instrument's proposed factor structure. Model modifications were used with caution, and applied only if a reasonable theoretical explanation existed (i.e., we only covaried error terms of items corresponding to the same latent factor). To evaluate the goodness of fit for the models, we used the fit indices and liberal cut-off values (see Hu \& Bentler, 1999). Since the $\chi^{2}$ is sensitive to sample size, we used $\chi^{2} / \mathrm{df}$ and root mean square of approximation (RMSEA; Steiger, 1990) for model evaluation: $\chi^{2} / \mathrm{df}$ smaller than 4 and RMSEA values smaller than .08 indicate a reasonable fit and values smaller than .05 a good fit (see MacCallum, Browne, \& Sugawara, 1996). A 90\% confidence interval (90\% CI) was also reported. For the comparative fit index (CFI; Bentler, 1990) and Tucker-Lewis index (TLI), values greater than .9 indicate a good fit, but values between .80 and .90 have been reported as satisfactory in the literature, especially for complex models using short measures (e.g., Atari, 2017). For the standardized root-mean-square residual (SRMR), values smaller than .09 indicated a good fit. Maximum likelihood (ML) estimation was used for model testing for all models. 
Measurement invariance (MI) testing included a series of model comparisons. At each comparison step, equality constraints were added consecutively to the models. Each model served as a basis for comparison to the preceding model. In the baseline model (configural invariance), no equality constraints were applied. This facilitated an evaluation of factor structures across samples. For testing weak invariance, factor loadings were constrained to be equal across different groups. If weak invariance was established, intercepts were also constrained to be equal across the groups (strong invariance). Imposing constraints on structural models always leads to decreases in model fit. To determine if the decrease in fit is substantial, initial studies used chi-square difference tests (Byrne, Shavelson, \& Muthén, 1989), but chisquare differences are also sensitive to sample size (Oishi, 2007). Thus, Cheung and Rensvold (2002) recommended a $\Delta$ CFI smaller or equal than .01 to indicate good measurement invariance. In addition to the chi-square difference test, we examined $\triangle \mathrm{CFI}$ and $\triangle \mathrm{RMSEA}$. We also report Bayesian information criterion (BIC) for all models, where smaller values indicate a superior solution to the trade-off between complexity and fit. If MI was evidenced, latent means were compared using independent-samples Welch-corrected $t$ tests. Effect sizes were reported using the effsize 0.7 (Torchiano, 2016). All CFIs and MIs were conducted with the R programming language and lavaan 0.6 package (Rosseel, 2012).

Multi-level models were run using lme4 1.1 package (Bates, Mächler, Bolker, \& Walker, 2015). In the multi-level models, we examined the sex effect nested in cultures, allowing sex differences in mate preferences to vary in the three cultures. Before allowing the sex effect to vary across countries, we calculated intraclass coefficients based on cultural differences. We calculated conditional R-squared to take both the effects of sex and country into account. Finally, we used linear regression models to examine the role of personality dimensions on mate 
preferences in different cultures. With regard to $p$ values, we pre-registered $p<.05$ as suggestive evidence and $p<.005$ as strong evidence for our statistical inferences (see Benjami et al., 2018). Pre-registration, data, and materials for this study are publicly available on Open Science Framework (https://osf.io/dws2a/?view_only=ec8ecbd90e9843ce839ad188f6fb5347).

\section{Results}

\section{Confirmatory Factor Analyses}

We began our analyses with three confirmatory factor analyses (CFAs) replicating the model proposed by Atari (2017). The five-factor model fit to the data from Iran was close to those reported by the parent study. We used "modification indices" to improve model fit by covarying error terms of items under a same dimension. The modified Iranian model (Figure 1) had adequate fit to the data $\left(\chi^{2} / \mathrm{DF}=2.06 ; \mathrm{CFI}=.90 ; \mathrm{TLI}=.88 ; \mathrm{RMSEA}=.065 ; \mathrm{RMSEA} 90 \% \mathrm{CI}\right.$ $[.055, .075] ; \mathrm{SRMR}=.068)$. We applied the same procedure to Pakistani data where the modified model (Figure 2$)$ showed good fit $\left(\chi^{2} / \mathrm{DF}=2.21 ; \mathrm{CFI}=.88 ; \mathrm{TLI}=.85 ; \mathrm{RMSEA}=.061 ; \mathrm{RMSEA}\right.$ 90\% CI [.052,.070]; SRMR =.067). The modified model for Turkish data (Figure 3) also showed acceptable fit to the data $\left(\chi^{2} / \mathrm{DF}=3.56 ; \mathrm{CFI}=.89 ; \mathrm{TLI}=.86 ; \mathrm{RMSEA}=.072 ; \mathrm{RMSEA}\right.$ $90 \%$ CI [.065,.078]; SRMR $=.086)$.

Figure 1

Modified Measurement Model in Iran 


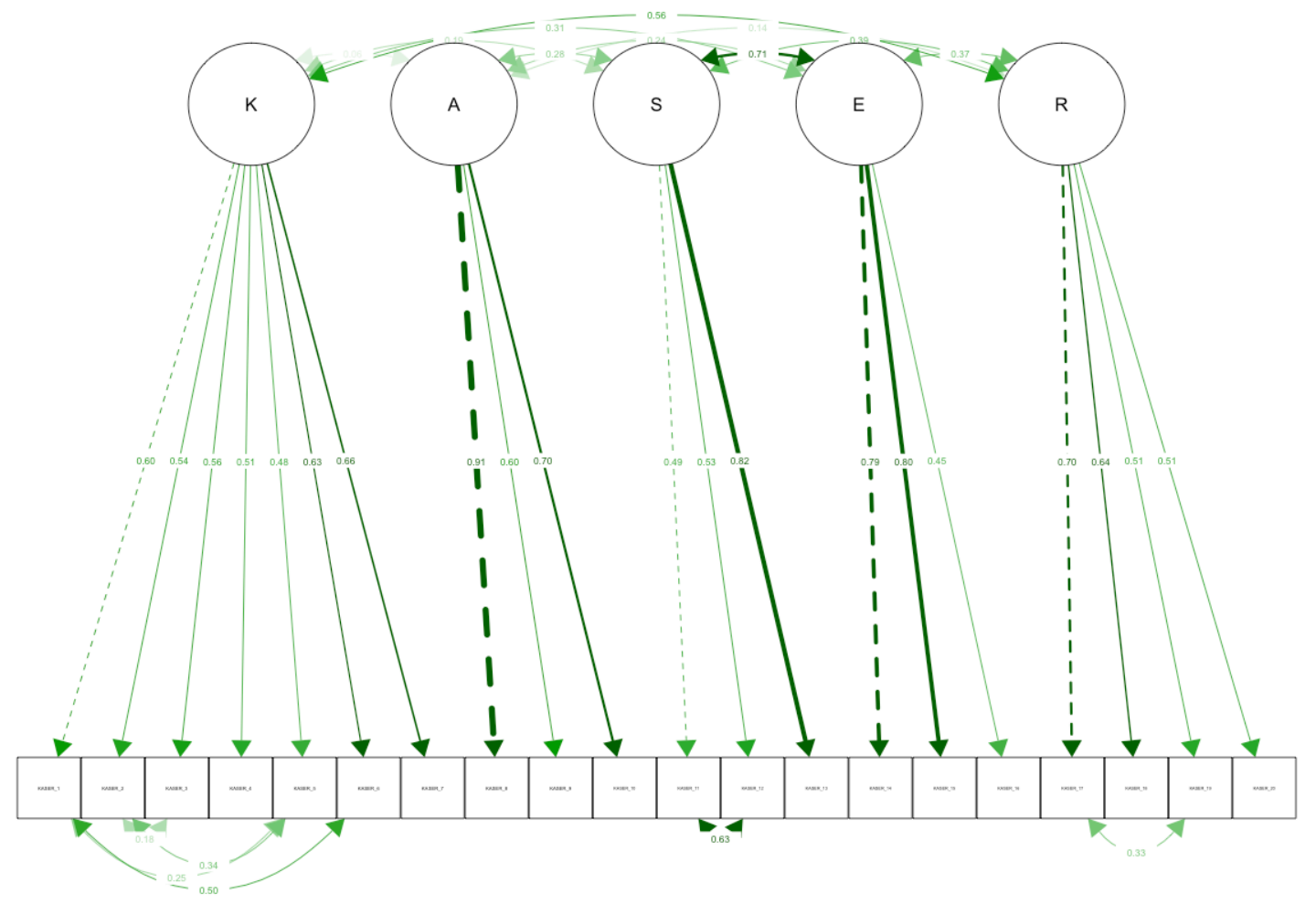

Figure 2

Modified Measurement Model in Pakistan 


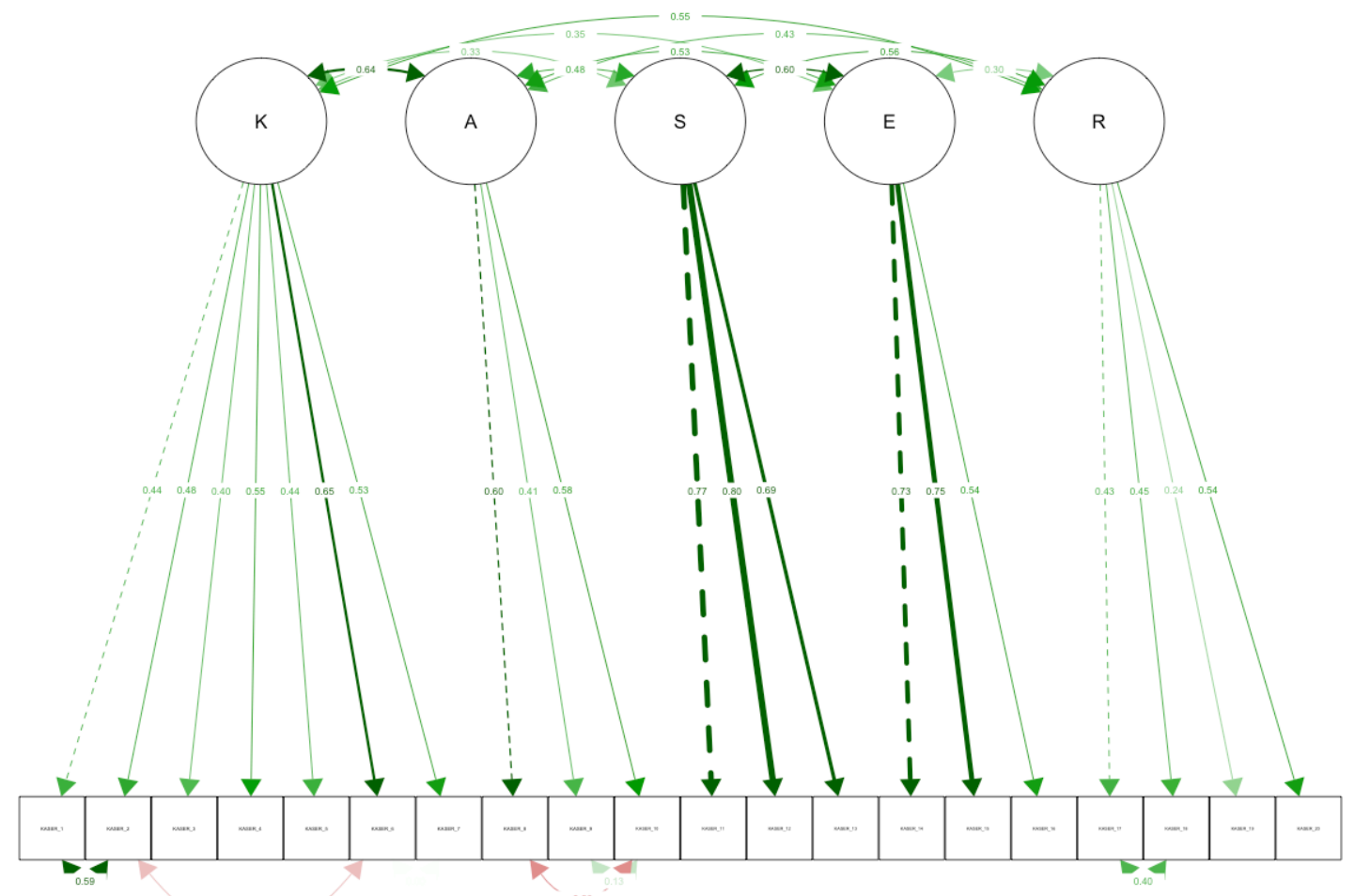

Figure 3

Modified Measurement Model in Turkey 


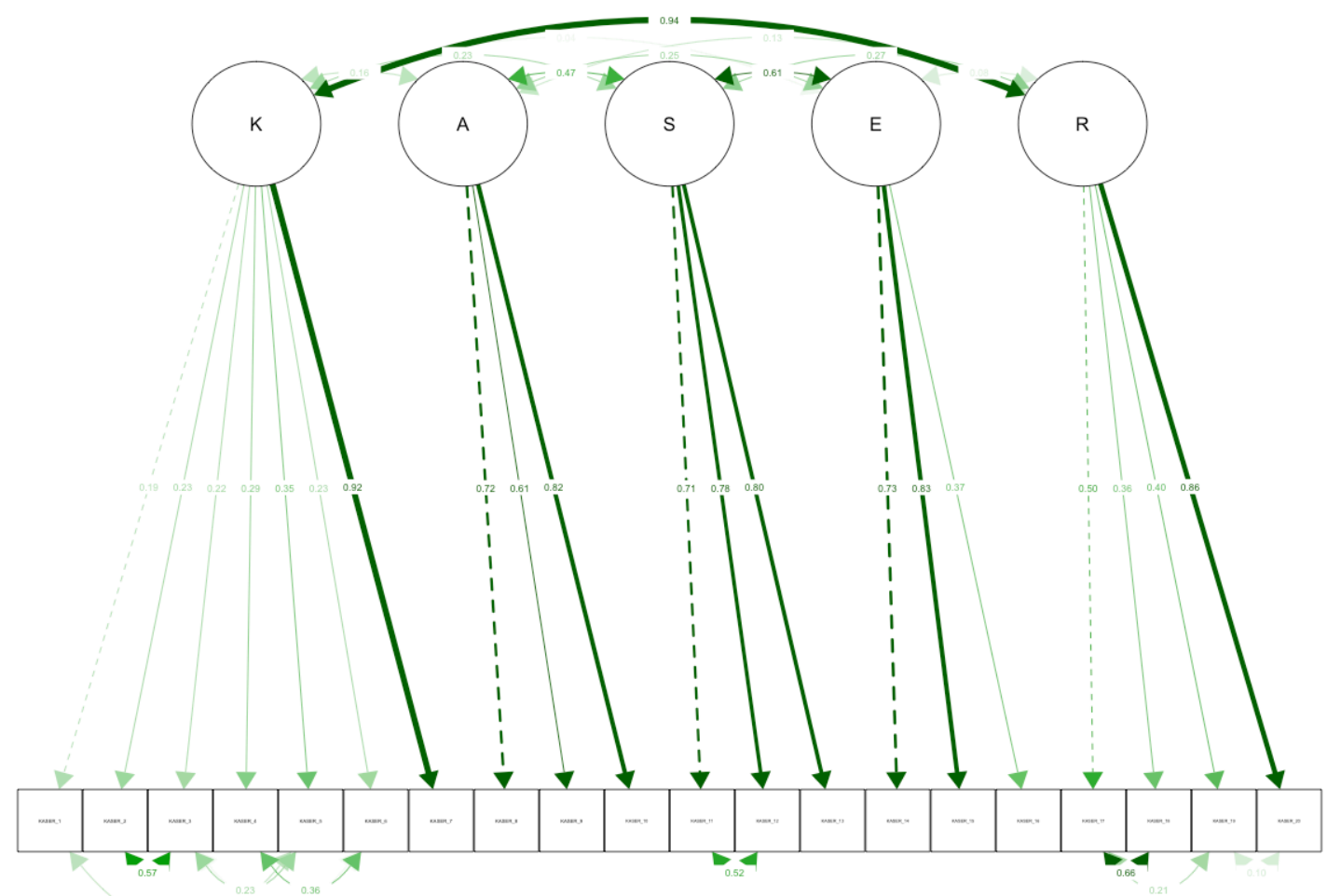

\section{Measurement Invariance and Sex Differences}

Although widely neglected in sex differences research, it is important to assess measurement invariance (MI) for men and women prior to examination of sex differences (Wang, Chen, Dai, \& Richardson, 2018). Drawing on original unmodified models (see Table 3), we established strong measurement invariance across sexes in Pakistan, Iran, and Turkey (see Table 4). As can be seen, BIC is lowest in the strong measurement invariance model in all three countries. In addition, model differences in CFI and RMSEA are mostly below recommended thresholds. Strong invariance (also known as scalar invariance) implies that not only the item loadings but also the item intercepts are similar across the groups. This form of measurement invariance implies that there are no systematic response biases and is required in order to meaningfully compare the means of latent variables across different groups (Chen, 2008). 
Therefore, we can meaningfully compare sex differences in the average scores of the dimensions of the measurement model.

Table 3

Results of Confirmatory Factor Analyses in Three Cultures

\begin{tabular}{lcccccc}
\hline Country & Model & $\chi 2 / \mathrm{DF}$ & CFI & TLI & RMSEA[90\%CI] & SRMR \\
\hline \multirow{2}{*}{ Iran } & Unmodified & 2.96 & .81 & .77 & $.088[.079, .098]$ & .082 \\
& Modified & 2.06 & .90 & .88 & $.065[.055, .075]$ & .068 \\
\multirow{2}{*}{ Pakistan } & Unmodified & 3.05 & .79 & .75 & $.079[.071, .088]$ & .091 \\
& Modified & 2.21 & .88 & .85 & $.061[.052, .070]$ & .067 \\
\multirow{2}{*}{ Turkey } & Unmodified & 5.63 & .79 & .75 & $.097[.091, .103]$ & .091 \\
& Modified & 3.56 & .89 & .86 & $.072[.065, .078]$ & .086 \\
\hline
\end{tabular}

Note. CFI = Comparative Fit Index; TLI = Tucker-Lewis Index; RMSEA = Root Mean Square of Approximation; SRMR = Standardized Root-Mean-square Residual.

Table 4

Sex Measurement Invariance Models in Three Cultures

\begin{tabular}{|c|c|c|c|c|c|c|c|c|c|c|c|}
\hline Country & Model & $x^{2}$ & $\Delta \chi^{2}$ & DF & $\Delta \mathrm{DF}$ & CFI & $\Delta \mathrm{CFI}$ & RMSEA & $\triangle \mathrm{RMSEA}$ & $p$ & $\mathrm{BIC}$ \\
\hline \multirow[t]{4}{*}{ Iran } & Configural & 633.73 & - & 320 & - & .81 & - & .088 & - & - & 9895 \\
\hline & Weak MI & 685.43 & 51.70 & 335 & 15 & .79 & .022 & .091 & .003 & $<.001$ & 9863 \\
\hline & Strong MI & 762.01 & 76.58 & 350 & 15 & .76 & .037 & .097 & .006 & $<.001$ & 9857 \\
\hline & Strict MI & 868.68 & 106.67 & 355 & 5 & .70 & .060 & .107 & .011 & $<.001$ & 9937 \\
\hline \multirow[t]{3}{*}{ Pakistan } & Configural & 667.03 & - & 320 & - & .78 & - & .082 & - & - & 15088 \\
\hline & Weak MI & 693.24 & 26.21 & 335 & 15 & .77 & .007 & .081 & .001 & .04 & 15027 \\
\hline & Strong MI & 724.36 & 31.13 & 350 & 15 & .76 & .010 & .081 & .000 & .01 & 14972 \\
\hline
\end{tabular}




\begin{tabular}{cccccccccccc}
\hline & Strict MI & 774.20 & 49.84 & 355 & 5 & .73 & .029 & .085 & .004 & $<.001$ & 14993 \\
\cline { 2 - 12 } Turkey & Configural & 1071.8 & - & 320 & - & .78 & - & .097 & - & - & 21082 \\
& Weak MI & 1096.7 & 24.96 & 335 & 15 & .78 & .003 & .096 & .002 & .05 & 21014 \\
& Strong MI & 1131.0 & 34.29 & 350 & 15 & .77 & .006 & .095 & .001 & .003 & 20955 \\
& Strict MI & 1266.1 & 135.09 & 355 & 5 & .73 & .038 & .102 & .007 & $<.001$ & 21059
\end{tabular}

Note MI = Measurement Invariance; DF = Degrees of Freedom; CFI = Comparative Fit Index; RMSEA

$=$ Root Mean Square of Approximation; BIC = Bayesian Information Criterion.

Next, we examined and visualized sex differences in dimensions of mate preferences in three cultures (see Figure 4 for violin plots, which are similar to box plots with the addition of a rotated kernel density plot on each side, appropriate for examining sex differences). The results are summarized in Table 5. As can be seen in Table 5, $H 1$ was supported in Iran and Turkey (i.e., men scored higher on desire for A). H2 was supported in all samples (i.e., women scored higher on S). H3 was supported in all samples (i.e., women scored higher on K). $H 4$ was supported in Iran and Turkey (i.e., women scored higher on E). Finally, although we did not have preregistered hypotheses about sex differences in preferences for Religiosity/chastity, Pakistani women showed stronger preference for religious/chaste romantic partners than did Pakistani men (Cohen's $d=-0.50)$.

Table 5

Sex Differences in Mate Preferences across Three Cultures

\begin{tabular}{|c|c|c|c|c|c|c|c|c|c|}
\hline & & Iran & & & Pakistan & & & Turkey & \\
\hline Factor & $\begin{array}{c}\text { Women's } \\
M(S D)\end{array}$ & $\begin{array}{l}\text { Men's } \\
M(S D)\end{array}$ & $\operatorname{Sex} d$ & $\begin{array}{c}\text { Women's } \\
M(S D)\end{array}$ & $\begin{array}{l}\text { Men's } \\
M(S D)\end{array}$ & $\operatorname{Sex} d$ & $\begin{array}{c}\text { Women's } \\
M(S D)\end{array}$ & $\begin{array}{l}\text { Men's } \\
M(S D)\end{array}$ & $\operatorname{Sex} d$ \\
\hline $\mathrm{K}$ & $3.83(0.28)$ & $3.75(0.32)$ & $-0.27 *$ & $3.30(0.45)$ & $3.18(0.50)$ & $-0.24 *$ & $3.45(0.38)$ & $3.27(0.43)$ & $-0.46 * *$ \\
\hline
\end{tabular}




\begin{tabular}{llllllllll}
\hline $\mathrm{A}$ & $2.96(0.67)$ & $3.26(0.65)$ & $0.46^{* *}$ & $2.99(0.57)$ & $3.05(0.58)$ & 0.10 & $2.51(0.63)$ & $2.68(0.61)$ & $0.28^{* *}$ \\
$\mathrm{~S}$ & $3.19(0.54)$ & $2.45(0.89)$ & $-0.99^{* *}$ & $3.12(0.61)$ & $2.70(0.85)$ & $-0.56^{* *}$ & $2.20(0.72)$ & $1.71(0.64)$ & $-0.70^{* *}$ \\
$\mathrm{E}$ & $3.20(0.69)$ & $3.01(0.72)$ & $-0.26^{*}$ & $3.11(0.63)$ & $3.04(0.75)$ & -0.10 & $3.04(0.71)$ & $2.70(0.73)$ & $-0.48^{* *}$ \\
$\mathrm{R}$ & $2.72(0.76)$ & $2.79(0.82)$ & 0.09 & $3.37(0.45)$ & $3.12(0.57)$ & $-0.50^{* *}$ & $1.77(0.78)$ & $1.69(0.74)$ & -0.09 \\
\hline
\end{tabular}

${ }^{*} p<.05$ (suggestive evidence) ${ }^{* *} p<.005$ (strong evidence)

Note. $\mathrm{K}=$ Kindness/dependability; $\mathrm{A}=$ Attractiveness/sexuality; $\mathrm{S}=$ Status/resources; $\mathrm{E}=$

Education/intelligence; $\mathrm{R}=$ Religiosity/chastity.

Figure 4

Violin Plots of Sex Differences in Mate Preferences 

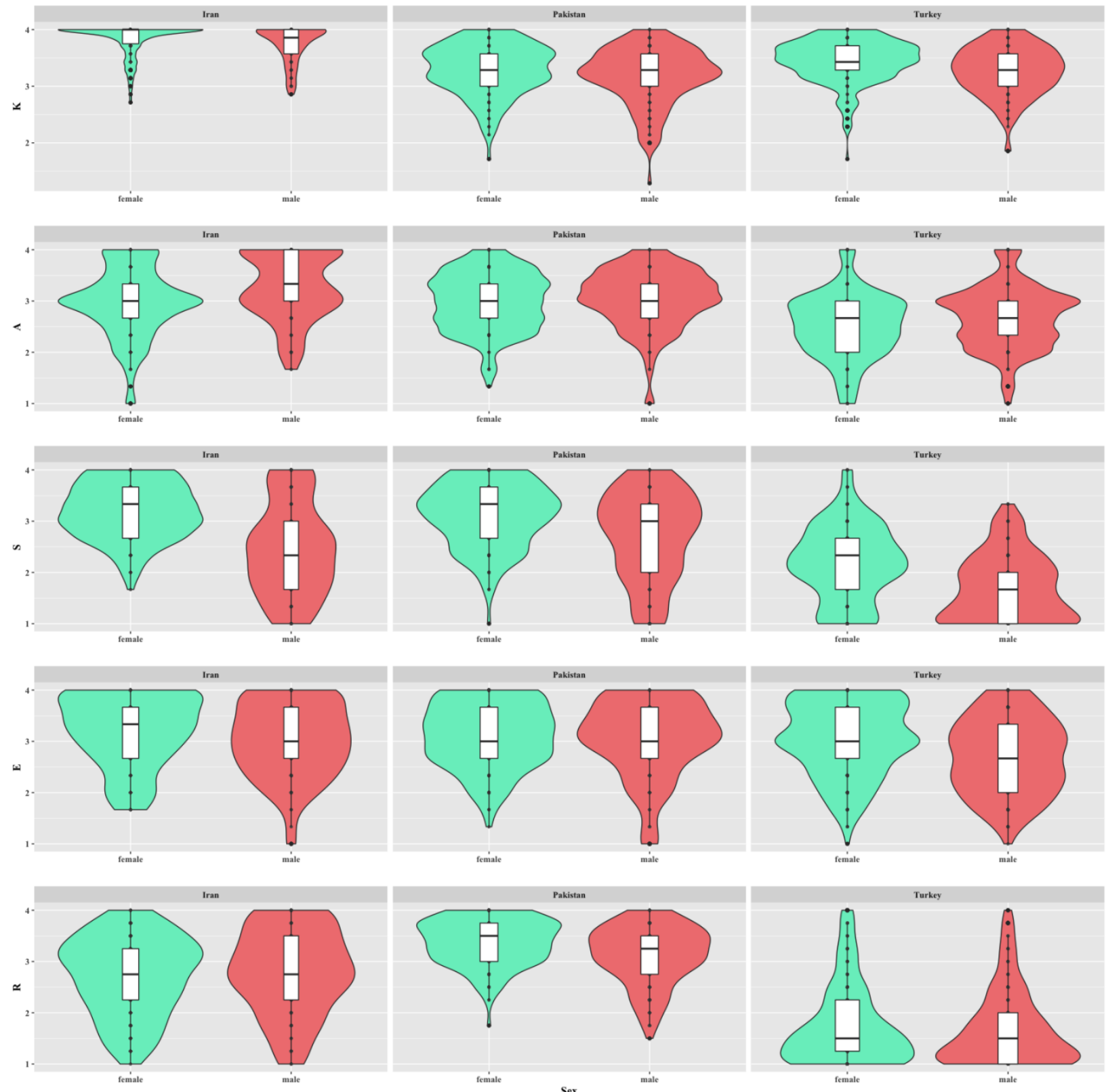

\section{Multi-Level Modeling}

We ran five series of multi-level models (MLMs) to examine how the effect of sex on mate preferences in nested in cultures. Our random-intercept MLMs are summarized in Table 6. In the $\mathrm{K}$ factor, the intraclass coefficient was .25 , indicating that $25 \%$ of $\mathrm{K}$ variations was explained at country-level. The mean sex effect across cultures was -0.14 scores $(S E=0.02, t=-$ 
4.67, $p<.01$ ), favoring women (Conditional $R^{2}=.27$ ). Varying the sex effect among cultures did not significantly improve the model $\left(\chi^{2}=0.80, \mathrm{df}=2, p=.67\right)$. Therefore, sex differences in $\mathrm{K}$ were not significantly variable across cultures. In the A factor, the intraclass coefficient was .12, indicating that $12 \%$ of $\mathrm{A}$ variations was explained at country-level. The mean sex effect across cultures was 0.17 scores $(S E=0.04, t=4.44, p<.01)$, favoring men (Conditional $\left.R^{2}=.13\right)$. Varying the sex effect among cultures did not significantly improve the model $\left(\chi^{2}=0.42\right.$, df $=2$, $p=.81)$. Therefore, sex differences in A were not significantly variable across cultures. In the $\mathrm{S}$ factor, the intraclass coefficient was .23, indicating that $23 \%$ of S variations was explained at country-level. The mean sex effect across cultures was -0.52 scores $(S E=0.04, t=-11.99, p<$ .01 ), favoring women (Conditional $R^{2}=.34$ ). Varying the sex effect among cultures did not significantly improve the model $\left(\chi^{2}=1.95, \mathrm{df}=2, p=.38\right)$. Therefore, sex differences in $\mathrm{S}$ were not significantly variable across cultures. In the E factor, the intraclass coefficient was .01, indicating that $1 \%$ of E variations was explained at country-level. The mean sex effect across cultures was -0.20 scores $(S E=0.04, t=-2.73, p<.01)$, favoring women (Conditional $\left.R^{2}=.04\right)$. Varying the sex effect among cultures did not significantly improve the model $\left(\chi^{2}=5.71\right.$, df $=2$, $p=.06)$. Therefore, sex differences in $\mathrm{E}$ were not significantly variable across cultures. In the $\mathrm{R}$ factor, the intraclass coefficient was .44 , indicating that $44 \%$ of $\mathrm{R}$ variations was explained at country-level. The mean sex effect across cultures was -0.10 scores $(S E=0.04, t=-2.22, p=$ .03 ), favoring women (Conditional $R^{2}=.45$ ). Varying the sex effect among cultures did not significantly improve the model $\left(\chi^{2}=2.24, \mathrm{df}=2, p=.33\right)$. Therefore, sex differences in $\mathrm{R}$ were not significantly variable across cultures. In sum, sex differences in all KASER traits were relatively invariant across cultures.

Table 6 
Multilevel Models Predicting Mate Preferences with Random-Intercept Effects of Sex

\begin{tabular}{lllll}
\hline Variable & ICC & Sex $(B)$ & $\operatorname{Sex}(S E)$ & $t$-value \\
\hline $\mathrm{K}$ & .25 & -0.14 & 0.02 & $-5.58^{* * *}$ \\
$\mathrm{~A}$ & .11 & 0.17 & 0.04 & $4.44 * * *$ \\
$\mathrm{~S}$ & .27 & -0.52 & 0.04 & $-11.99 * * *$ \\
$\mathrm{E}$ & .02 & -0.22 & 0.04 & $-5.15^{* * *}$ \\
$\mathrm{R}$ & .45 & -.010 & 0.04 & $-2.22 *$ \\
\hline$* \mathrm{p}<.05, * * * \mathrm{p}<.001$ Note. $\mathrm{K}=\mathrm{ICC}=$ Intra-Class Correlation; Kindness/dependability; $\mathrm{A}=$
\end{tabular}

Attractiveness/sexuality; $\mathrm{S}=$ Status/resources; $\mathrm{E}=$ Education/intelligence; $\mathrm{R}=$ Religiosity/chastity.

Personality and Mate Preferences

We ran five distinct sets of regressions in three countries with five dimensions of mate preferences as dependent variables and the Big Five personality dimensions as independent variables. Model estimates of these regression models are summarized in Tables 7-9. H5 was supported in two cultures: in Iran and Turkey, individuals who scored higher on Openness to Experience preferred less religious partners. $H 6 a$ was supported in all three countries, but $H 6 b$ was not supported (i.e., more agreeable individuals prefer more kind/dependable partners in all cultures, but we found no evidence between Agreeableness and preference for Religiosity/chastity). Conscientiousness was positively associated with Kindness/dependability and Religiosity/chastity in Iran, but not Pakistan or Turkey. Therefore, $H 7 a$ and $H 7 b$ were not supported in Pakistan and Turkey. 
Table 7

Regression Estimates of Personality Dimensions Predicting Mate Preferences in Iran

\begin{tabular}{|c|c|c|c|c|c|c|c|c|c|c|c|c|c|c|c|c|c|c|c|c|}
\hline & \multicolumn{20}{|c|}{ Iran } \\
\hline & \multicolumn{4}{|c|}{$\mathrm{K}$} & \multicolumn{4}{|c|}{$\mathrm{A}$} & \multicolumn{4}{|c|}{$\mathrm{S}$} & \multicolumn{4}{|c|}{ 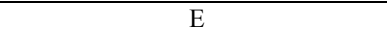 } & \multicolumn{4}{|c|}{$\mathrm{R}$} \\
\hline & $B$ & $t$ & $p$ & $95 \% C I$ & $B$ & $t$ & $p$ & $95 \% C I$ & $B$ & $t$ & $p$ & $95 \% C I$ & $B$ & $t$ & $p$ & $95 \% C I$ & $B$ & $t$ & $p$ & $95 C I$ \\
\hline Extraversion & .008 & 1.36 & .176 & $\begin{array}{c}{[-.004} \\
.019]\end{array}$ & .011 & 0.82 & .413 & $\begin{array}{c}{[-.016} \\
.038]\end{array}$ & .018 & 1.14 & .255 & $\begin{array}{c}{[-.013} \\
.050]\end{array}$ & -.006 & -0.43 & .667 & $\begin{array}{c}{[-.034} \\
.022]\end{array}$ & .020 & 1.29 & .198 & $\begin{array}{c}{[-.010} \\
.049]\end{array}$ \\
\hline Agreeableness & .040 & 4.86 & .000 & $\begin{array}{c}{[.024} \\
.056]\end{array}$ & -.019 & -1.01 & .313 & $\begin{array}{c}{[-.057} \\
.018]\end{array}$ & .039 & 1.72 & .086 & $\begin{array}{c}{[-.006} \\
.084]\end{array}$ & .002 & 0.11 & .915 & $\begin{array}{c}{[-.038} \\
.042]\end{array}$ & .040 & 1.90 & .059 & $\begin{array}{l}{[.002} \\
.082]\end{array}$ \\
\hline Conscientiousness & .017 & 2.53 & .012 & $\begin{array}{c}{[.004} \\
.030]\end{array}$ & -.002 & -0.15 & .881 & $\begin{array}{c}{[-.034} \\
.029]\end{array}$ & .017 & 0.93 & .355 & $\begin{array}{c}{[-.020} \\
.054]\end{array}$ & -.019 & -1.16 & .248 & $\begin{array}{c}{[-.052} \\
.014]\end{array}$ & .040 & 2.29 & .023 & $\begin{array}{l}{[.006} \\
.075]\end{array}$ \\
\hline Emotional Stability & -.009 & -1.44 & .152 & $\begin{array}{c}{[-.021} \\
.003]\end{array}$ & -.012 & -0.82 & .411 & $\begin{array}{c}{[-.040} \\
.016]\end{array}$ & -.044 & -2.61 & .010 & $\begin{array}{c}{[-.077,-} \\
.011]\end{array}$ & -.021 & -1.41 & .161 & $\begin{array}{c}{[-.051} \\
.008]\end{array}$ & -.010 & -0.63 & .529 & $\begin{array}{c}{[-.041} \\
.021]\end{array}$ \\
\hline Openness to Experience & -.006 & -0.87 & .388 & $\begin{array}{c}{[-.021} \\
.008]\end{array}$ & .002 & 0.09 & .929 & $\begin{array}{c}{[-.033} \\
.036]\end{array}$ & .013 & 0.62 & .537 & $\begin{array}{c}{[-.028} \\
.054]\end{array}$ & -.006 & -0.33 & .740 & $\begin{array}{c}{[-.042} \\
.030]\end{array}$ & -.090 & -4.63 & .000 & $\begin{array}{c}{[-.128,-} \\
.051]\end{array}$ \\
\hline Model R2 & & & .12 & & & & 10 & & & & .04 & & & & 02 & & & & .12 & \\
\hline
\end{tabular}

Note. $\mathrm{K}=$ Kindness/dependability; $\mathrm{A}=$ Attractiveness/sexuality; $\mathrm{S}=$ Status/resources; $\mathrm{E}=$ Education/intelligence; $\mathrm{R}=$ Religiosity/chastity. 
Table 8

Regression Estimates of Personality Dimensions Predicting Mate Preferences in Pakistan

\begin{tabular}{|c|c|c|c|c|c|c|c|c|c|c|c|c|c|c|c|c|c|c|c|c|}
\hline & \multicolumn{20}{|c|}{ Pakistan } \\
\hline & \multicolumn{4}{|c|}{$\mathrm{K}$} & \multicolumn{4}{|c|}{ A } & \multicolumn{4}{|c|}{$\mathrm{S}$} & \multicolumn{4}{|c|}{$\bar{E}$} & \multicolumn{4}{|c|}{$\mathrm{R}$} \\
\hline & $B$ & $t$ & $p$ & $95 \% C I$ & $B$ & $t$ & $\bar{p}$ & $95 \% C I$ & $B$ & $t$ & $\bar{p}$ & $95 \% C I$ & $B$ & $t$ & $p$ & $95 \% C I$ & $B$ & $t$ & $p$ & $95 \% C I$ \\
\hline Extraversion & .036 & 3.15 & .002 & $\begin{array}{l}{[.013,} \\
.058]\end{array}$ & .023 & 1.61 & .108 & $\begin{array}{c}{[-.005,} \\
.050]\end{array}$ & .028 & 1.52 & .131 & $\begin{array}{l}{[-.008,} \\
.064]\end{array}$ & .008 & 0.47 & .642 & $\begin{array}{c}{[-.025,} \\
.040]\end{array}$ & .010 & 0.79 & .429 & $\begin{array}{c}{[-.015,} \\
.035]\end{array}$ \\
\hline Agreeableness & .038 & 2.92 & .004 & $\begin{array}{l}{[.012,} \\
.064]\end{array}$ & .009 & 0.54 & .587 & $\begin{array}{c}{[-.023} \\
.041]\end{array}$ & -.005 & -0.24 & .813 & $\begin{array}{l}{[-.047,} \\
.037]\end{array}$ & -.024 & -1.24 & .218 & $\begin{array}{c}{[-.062} \\
.014]\end{array}$ & .003 & 0.18 & .854 & $\begin{array}{c}{[-.027,} \\
.032]\end{array}$ \\
\hline Conscientiousness & .010 & 0.79 & .429 & $\begin{array}{c}{[-.014,} \\
.034]\end{array}$ & -.006 & -0.41 & .685 & $\begin{array}{c}{[-.036} \\
.024]\end{array}$ & -.043 & -2.16 & .031 & $\begin{array}{c}{[-.082,-} \\
.004]\end{array}$ & -.035 & -1.96 & .051 & $\begin{array}{c}{[-.070} \\
.000]\end{array}$ & -.007 & -0.54 & .591 & $\begin{array}{c}{[-.035,} \\
.020]\end{array}$ \\
\hline Emotional Stability & .014 & 1.11 & .269 & $\begin{array}{c}{[-.011,} \\
.038]\end{array}$ & .012 & 0.75 & .451 & $\begin{array}{c}{[-.019} \\
.042]\end{array}$ & -.008 & -0.42 & .678 & $\begin{array}{l}{[-.048,} \\
.031]\end{array}$ & .035 & 1.91 & .057 & $\begin{array}{c}{[-.001} \\
.071]\end{array}$ & .019 & 1.35 & .177 & $\begin{array}{c}{[-.009,} \\
.047]\end{array}$ \\
\hline Openness to Experience & .003 & 0.24 & .808 & $\begin{array}{c}{[-.023,} \\
.029]\end{array}$ & -.010 & -0.63 & .530 & $\begin{array}{c}{[-.043} \\
.022]\end{array}$ & -.039 & -1.78 & .076 & $\begin{array}{l}{[-.082,} \\
.004]\end{array}$ & -.041 & -2.12 & .035 & $\begin{array}{c}{[-.080,-} \\
.003]\end{array}$ & -.030 & -1.97 & .050 & $\begin{array}{c}{[-.060,} \\
.000]\end{array}$ \\
\hline Model $R^{2}$ & & & 7 & & & & 01 & & & & 04 & & & & 04 & & & & 2 & \\
\hline
\end{tabular}

Note. $\mathrm{K}=$ Kindness/dependability; $\mathrm{A}=$ Attractiveness/sexuality; $\mathrm{S}=$ Status/resources; $\mathrm{E}=$ Education/intelligence; $\mathrm{R}=$ Religiosity/chastity. 
Table 9

Regression Estimates of Personality Dimensions Predicting Mate Preferences in Turkey

\begin{tabular}{|c|c|c|c|c|c|c|c|c|c|c|c|c|c|c|c|c|c|c|c|c|}
\hline & \multicolumn{20}{|c|}{ Turkey } \\
\hline & \multicolumn{4}{|c|}{$\mathrm{K}$} & \multicolumn{4}{|c|}{$\bar{A}$} & \multicolumn{4}{|c|}{$\mathrm{S}$} & \multicolumn{4}{|c|}{$\mathrm{E}$} & \multicolumn{4}{|c|}{$\mathrm{R}$} \\
\hline & $B$ & $t$ & $p$ & $95 \% C I$ & $B$ & $t$ & $p$ & $95 \% C I$ & $B$ & $t$ & $p$ & $95 \% C I$ & $B$ & $t$ & $p$ & $95 \% C I$ & $B$ & $t$ & $p$ & $95 \% C I$ \\
\hline Extraversion & .013 & 2.02 & .044 & $\begin{array}{l}.000, \\
.026]\end{array}$ & .008 & 0.77 & .442 & $\begin{array}{c}-.012, \\
.028]\end{array}$ & .024 & 2.05 & .040 & $\begin{array}{l}.001, \\
.047]\end{array}$ & .019 & 1.60 & .111 & $\begin{array}{c}-.004, \\
.042]\end{array}$ & .003 & 0.25 & .805 & $\begin{array}{c}{[-.021,} \\
.027]\end{array}$ \\
\hline Agreeableness & .023 & 3.19 & .002 & $\begin{array}{l}{[.009,} \\
.038]\end{array}$ & .005 & 0.45 & .650 & $\begin{array}{c}{[-.018} \\
.028]\end{array}$ & .019 & 1.43 & .154 & $\begin{array}{c}{[-.007,} \\
.045]\end{array}$ & -.001 & -0.11 & .914 & $\begin{array}{c}{[-.028} \\
.025]\end{array}$ & .016 & 1.16 & .249 & $\begin{array}{c}{[-.011,} \\
.044]\end{array}$ \\
\hline Conscientiousness & .011 & 1.55 & .121 & $\begin{array}{l}{[-.003,} \\
.024]\end{array}$ & -.001 & -0.13 & .901 & $\begin{array}{c}{[-.022,} \\
.020]\end{array}$ & .014 & 1.14 & .254 & $\begin{array}{c}{[-.010} \\
.038]\end{array}$ & -.006 & -0.49 & .624 & $\begin{array}{c}{[-.031,} \\
.018]\end{array}$ & .010 & 0.77 & .443 & $\begin{array}{c}{[-.015} \\
.035]\end{array}$ \\
\hline Emotional Stability & .008 & 1.12 & .263 & $\begin{array}{c}{[-.006} \\
.022]\end{array}$ & .019 & 1.69 & .092 & $\begin{array}{c}{[-.003} \\
.042]\end{array}$ & -.035 & -2.68 & .008 & $\begin{array}{c}{[-.061,-} \\
.009]\end{array}$ & -.018 & -1.36 & .176 & $\begin{array}{c}{[-.044,} \\
.008]\end{array}$ & -.001 & -0.06 & .953 & $\begin{array}{c}{[-.028,} \\
.026]\end{array}$ \\
\hline Openness to Experience & -.015 & -2.41 & .016 & $\begin{array}{c}{[-.027,-} \\
.003]\end{array}$ & -.012 & -1.25 & .212 & $\begin{array}{c}{[-.031,} \\
.007]\end{array}$ & -.031 & -2.81 & .005 & $\begin{array}{c}{[-.053,-} \\
.009]\end{array}$ & -.009 & -0.78 & .433 & $\begin{array}{c}{[-.031} \\
.013]\end{array}$ & -.027 & -2.33 & .020 & $\begin{array}{r}{[-.050,-} \\
.004]\end{array}$ \\
\hline Model $R^{2}$ & & & 5 & & & & 1 & & & & $\overline{04}$ & & & & 1 & & & & 01 & \\
\hline
\end{tabular}

Note. $\mathrm{K}$ = Kindness/dependability; A = Attractiveness/sexuality; $\mathrm{S}$ = Status/resources; $\mathrm{E}=$ Education/intelligence; $\mathrm{R}=$ Religiosity/chastity. 


\section{Discussion}

As we predicted in our pre-registration, sex differences in dimensions of mate preferences largely replicated previous findings. Specifically, our multi-level models revealed that women-more than men — valued kindness, dependability, good parenting characteristics, status, resources, education, and intelligence in a potential romantic partner. Men, on the other hand, consistently scored higher on the preference for attractiveness. We found strong support for these pre-registered hypotheses $(H 1-H 4)$. This study therefore provides support for wellestablished evolutionary hypotheses about sex differences in mate preferences, and is one of the first studies to do so in Middle Eastern, Muslim-majority countries (for exceptions see Atari, 2017 and Buss, 1989).

We also found some-culture-specific effects. We found, on an exploratory basis, that women in Pakistan put more emphasis on religiosity and chastity than do men, which might be attributable to cultural norms in Pakistan. Yet, this effect should be treated with uncertainty until further replicated in future research.

We found that the magnitude of sex differences in mate preferences, indexed by nonsignificant changes in model fit in MLMs, was relatively invariant across cultures. Cultures varied in their average level of mate preferences. For example, Figure 4 clearly shows how these three cultures have very different average-level preferences for religiosity and chastity. However, once we included sex in our multilevel models, cross-cultural variation was attenuated.

Moderate and mixed associations were detected between individuals' scores on the Big Five personality dimensions and their mate preferences on the KASER scale. We found that Openness to Experience predicts preferences for less religious partners in Iran and Turkey, but not in Pakistan. Open individuals tend to report slightly lower levels of religiosity in Iran and 
Turkey, but not in Pakistan (e.g., Gebauer et al., 2014). It may therefore be the case that more open individuals in Iran and Turkey are less religious and prefer mates with similar levels of religiosity. However, our personality measure did not perform well in Pakistan, with unexpected negative inter-item correlations, suggesting that TIPI's subscales may not be reliably measuring the Big Five personality dimensions in Pakistan.

Consistent with our expectation, Agreeableness predicted preference for kindness and dependable character in all cultures, but (contrary to our prediction) we found no evidence that Agreeableness predicts individuals' preferences for religious or chaste partners. Agreeable individuals are less likely to commit infidelity (Bourdage, Lee, Ashton, \& Perry, 2007) and are generally "kind", "sympathetic", and "considerate" (Costa \& McCrae, 1992). It stands to reason, therefore, that while characteristics associated with Agreeableness are generally preferred by all individuals (Strouts, Brase, \& Dillon, 2017), those who score higher on Agreeableness place an even greater importance on these characteristics.

In the context of romantic relationships, people who score high on Conscientiousness are more likely to remain exclusive (Bourdage et al., 2007) and participate in more religious traditions (Afhami, Mohammadi-Zarghan, \& Atari, 2017). Individuals who score higher on Conscientiousness tend to prefer romantic partners who have similar characteristics (Botwin, Buss, \& Shackelford, 1997). We predicted that more conscientious individuals would prefer more dependable and religious mates. These effects were found in Iran, but not in Pakistan or Turkey. The role of Conscientiousness in mate selection preferences in different cultures should therefore be treated with caution.

Together, our results are consistent with the notion that people's preferences are guided by their basic personality dimensions, at least to some extent (see Youyou, Schwartz, Stillwell, \& 
Kosinski, 2017). Rather than personality-personality analysis (e.g., conscientious individuals prefer conscientious partners; see Štěrbová et al., 2017), we examined the associations between personality dimensions and an established model of long-term mate preferences (e.g., conscientious individuals prefer kind, understanding, religious, and chaste partners). There is convincing evidence that other personality traits, not examined here (e.g., narcissism; Atari \& Chegeni, 2017), predict a preference for Attractiveness/sexuality. This calls for further research on the relationships between different personality models (e.g., HEXACO; Lee \& Ashton, 2004) and the KASER model of long-term mate preferences in different cultures.

The present research had several strengths, including its cross-cultural samples from understudied Muslim-majority nations and its use of a novel, dimensional model of mate preferences. However, the present study also had some limitations. One such limitation is that most participants in the present study were from urban areas in Iran, Pakistan, and Turkey, leaving out rural areas and subcultures within these countries. Future research would do well to include more rural areas of non-WEIRD cultures. Second, we used a short measure of the Big Five (Gosling et al., 2003), which showed unexpectedly poor inter-item correlations, especially in Pakistan (see Table 2). Future research may benefit from using longer measures of the Big Five (e.g., Big Five Inventory-2; Soto \& John, 2017). In addition to trait-level analysis of the relationship between the Big Five and mate preferences, we suggest facet-level analyses which are feasible using recently developed measures of the Big Five (e.g., BFI-2). We strongly recommend replicating these results in independent samples since multiple Urdu measures failed to meet conventional (or liberal) thresholds for internal consistency. It would also be instructive to examine the associations between people's ratings of their own characteristics on the KASER model and their mate preferences using this model (see Conroy-Beam \& Buss, 2016). Finally, 
this study used cross-sectional data and correlational analyses. It is therefore important not to draw any firm causal conclusions from the present findings that personality traits predict mate preferences.

\section{Conclusion}

The current research is the first systematic pre-registered examination of mate preferences in understudied Muslim-majority countries in the Middle East. We provide evidence that the KASER model of mate preferences (Atari, 2017) has adequate measurement qualities in Farsi, Urdu, and Turkish, and that its scores can be meaningfully compared between men and women (indexed by strong measurement invariance). Consistent with our hypotheses and with previous evolutionary psychological research, robust sex differences in mate preferences emerged in these cultures, such that women showed a stronger preference for kindness/dependability, status/resources, and education/intelligence, whereas men showed a stronger preference for attractiveness/sexuality. Examination of personality correlates of mate preferences showed that the Big Five dimension of Agreeableness consistently predicts preferences for kind and dependable romantic partners and Openness to Experience predicts preference for less religious partners in Iran and Turkey. We hope that these findings motivate researchers to continue studying mate preferences and personality, and to do so especially in understudied Muslim-majority countries. 


\section{References}

Abele, A. E., Cuddy, A. J. C., Judd, C. M., \& Yzerbyt, V. Y. (2008). Fundamental dimensions of social judgment. European Journal of Social Psychology, 38, 1063-1065.

Afhami, R., Mohammadi-Zarghan, S., \& Atari, M. (2017). Self-Rating of Religiosity (SRR) in Iran: Validity, reliability, and associations with the Big Five. Mental Health, Religion \& Culture, 20(9), 879-887.

Atak, H. (2013). The Turkish adaptation of the ten-item personality inventory. Nöro Psikiyatri Arşivi, 50, 312-319.

Atari, M. (2017). Assessment of long-term mate preferences in Iran. Evolutionary Psychology, $15,1474704917702459$.

Atari, M., \& Chegeni, R. (2017). The Dark Triad and long-term mate preferences in Iranian women. Personality and Individual Differences, 104, 333-335.

Atari, M., Chegeni, R., \& Fathi, L. (2017). Women who are interested in cosmetic surgery want it all: The association between considering cosmetic surgery and women's mate preferences. Adaptive Human Behavior and Physiology, 3, 61-70.

Atari, M., \& Jamali, R. (2016). Dimensions of women's mate preferences: Validation of a mate preference scale in Iran. Evolutionary Psychology, 14, 1474704916651443.

Bech-Sørensen, J., \& Pollet, T. V. (2016). Sex differences in mate preferences: A replication study, 20 years later. Evolutionary Psychological Science, 2, 171-176.

Bourdage, J. S., Lee, K., Ashton, M. C., \& Perry, A. (2007). Big Five and HEXACO model personality correlates of sexuality. Personality and Individual Differences, 43, 15061516. 
Bates, D., Mächler, M., Bolker, B., \& Walker, S. (2015). Fitting linear mixed-effects models using lme4. Journal of Statistical Software, 67, 1-48.

Benjamin, D. J., Berger, J. O., Johannesson, M., Nosek, B. A., Wagenmakers, E. J., Berk, R., ... \& Cesarini, D. (2018). Redefine statistical significance. Nature Human Behaviour, 2, 6.

Bentler, P. M. (1990). Comparative fit indexes in structural models. Psychological Bulletin, 107, 238-246.

Botwin, M. D., Buss, D. M., \& Shackelford, T. K. (1997). Personality and mate preferences: Five factors in mate selection and marital satisfaction. Journal of Personality, 65, 107136.

Boysen, G. A. (2017). Stigma toward people with mental illness as potential sexual and romantic partners. Evolutionary Psychological Science, 3, 212-223.

Brislin, R. W. (1970). Back-translation for cross-cultural research. Journal of Cross-Cultural Psychology, 1, 185-216.

Byrne, B. M., Shavelson, R. J., \& Muthén, B. (1989). Testing for the equivalence of factor covariance and mean structures: The issue of partial measurement invariance. Psychological Bulletin, 105, 456- 466.

Buckels, E. E., Beall, A. T., Hofer, M. K., Lin, E. Y., Zhou, Z., \& Schaller, M. (2015). Individual differences in activation of the parental care motivational system: Assessment, prediction, and implications. Journal of Personality and Social Psychology, 108, 497-514.

Buss, D. M. (1984). Marital assortment for personality dispositions: Assessment with three different data sources. Behavior Genetics, 14, 111-123.

Buss, D. M. (1989). Sex differences in human mate preferences: Evolutionary hypotheses tested in 37 cultures. Behavioral and Brain Sciences, 12, 1-49. 
Buss, D. M., \& Barnes, M. (1986). Preferences in human mate selection. Journal of Personality and Social Psychology, 50, 559-570.

Buss, D. M., \& Schmitt, D. P. (1993). Sexual strategies theory: an evolutionary perspective on human mating. Psychological Review, 100, 204-232.

Chaudhary, N., Al-Shawaf, L., \& Buss, D. M. (2018). Mate competition in Pakistan: Mate value, mate retention, and competitor derogation. Personality and Individual Differences, 130, 141-146.

Chegeni, R., Pirkalani, R. K., \& Dehshiri, G. (2018). On love and darkness: The Dark Triad and mate retention behaviors in a non-Western culture. Personality and Individual Differences, 122, 43-46.

Chen, F. F. (2008). What happens if we compare chopsticks with forks? The impact of making inappropriate comparisons in cross-cultural research. Journal of Personality and Social Psychology, 95, 1005-1018.

Cheung, G. W., \& Rensvold, R. B. (2002). Evaluating goodness-of-fit indexes for testing measurement invariance. Structural Equation Modeling, 9, 233-255.

Conroy-Beam, D., \& Buss, D. M. (2016). Do mate preferences influence actual mating decisions? Evidence from computer simulations and three studies of mated couples. Journal of Personality and Social Psychology, 111, 53-66.

Cortina, J. M. (1993). What is coefficient alpha? An examination of theory and applications. Journal of Applied Psychology, 78, 98-104.

Costa, P.T., \& McCrae, R.R. (1992). Revised NEO Personality Inventory (NEO-PI-R) and the NEO Five-Factor Inventory (NEO-FFI): Professional manual. Odessa, FL: Psychological Assessment Resources, Inc. 
Diener, E., \& Seligman, M. E. (2002). Very happy people. Psychological Science, 13, 81-84.

Eastwick, P. W., \& Finkel, E. J. (2008). Sex differences in mate preferences revisited: Do people know what they initially desire in a romantic partner? Journal of Personality and Social Psychology, 94, 245-264.

Fletcher, G. J. O., Simpson, J. A., Thomas, G., \& Giles, L. (1999). Ideals in intimate relationships. Journal of Personality and Social Psychology, 76, 72-89.

Gebauer, J. E., Bleidorn, W., Gosling, S. D., Rentfrow, P. J., Lamb, M. E., \& Potter, J. (2014). Cross-cultural variations in Big Five relationships with religiosity: A sociocultural motives perspective. Journal of Personality and Social Psychology, 107, 1064-1091.

Gebauer, J. E., Leary, M. R., \& Neberich, W. (2012). Big Two personality and Big Three mate preferences: Similarity attracts, but country-level mate preferences crucially matter. Personality and Social Psychology Bulletin, 38, 1579-1593.

Gosling, S. D., Rentfrow, P. J., \& Swann, W. B. (2003). A very brief measure of the Big-Five personality domains. Journal of Research in Personality, 37, 504-528.

Henrich, J., Heine, S. J., \& Norenzayan, A. (2010). Most people are not WEIRD. Nature, 466, 29.

Hill, S. E., \& Buss, D. M. (2006). Envy and positional bias in the evolutionary psychology of management. Managerial and Decision Economics, 27, 131-143.

Hu, L. T., \& Bentler, P. M. (1999). Cutoff criteria for fit indexes in covariance structure analysis: Conventional criteria versus new alternatives. Structural Equation Modeling, 6, 1-55.

Kamble, S., Shackelford, T. K., Pham, M., \& Buss, D. M. (2014). Indian mate preferences: Continuity, sex differences, and cultural change across a quarter of a century. Personality and Individual Differences, 70, 150-155. 
Kawamichi, H., Sugawara, S. K., Hamano, Y. H., Makita, K., Matsunaga, M., Tanabe, H. C., ... \& Sadato, N. (2016). Being in a romantic relationship is associated with reduced gray matter density in striatum and increased subjective happiness. Frontiers in Psychology, 7, 1763.

Khan, B., Ahmed, A., \& Abid, G. (2016). Using the 'Big-Five' for assessing personality traits of the champions: An insinuation for the sports industry. Pakistan Journal of Commerce and Social Sciences, 10, 175-191.

Kline, R. B. (2010). Principles and practice of structural equation modeling ( $3 \mathrm{rd}$ ed.). New York, NY: Guilford Press.

Lee, K., \& Ashton, M. C. (2004). Psychometric properties of the HEXACO personality inventory. Multivariate Behavioural Research, 39, 329-358.

Lewis, D. M., Al-Shawaf, L., \& Yilmaz, C. (2015). The Openness-calibration hypothesis. Personality and Individual Differences, 81, 53-60.

Li, N. P., Bailey, J. M., Kenrick, D. T., \& Linsenmeier, J. A. (2002). The necessities and luxuries of mate preferences: Testing the tradeoffs. Journal of Personality and Social Psychology, 82, 947-955.

MacCallum, R. C., Browne, M. W., \& Sugawara, H. M. (1996). Power analysis and determination of sample size for covariance structure modeling. Psychological Methods, $1,130-149$

Meltzer, A. L., McNulty, J. K., Jackson, G. L., \& Karney, B. R. (2014). Sex differences in the implications of partner physical attractiveness for the trajectory of marital satisfaction. Journal of Personality and Social Psychology, 106, 418-428. 
Oishi, S. (2007). The application of structural equation modeling and item response theory to cross-cultural positive psychology research. In A. D. Ong \& M. H. M. van Dulmen (Eds.), Oxford handbook of methods in positive psychology (pp. 126-138). New York, NY: Oxford University Press.

R Core Team (2017). R: A language and environment for statistical computing. R Foundation for Statistical Computing. Vienna, Austria. URL https://www.R-project.org/.

Revelle, W. (2017). psych: Procedures for Personality and Psychological Research. Northwestern University, Evanston, Illinois, USA. Retrieved from https://cran.rproject.org/package=psych

Rosseel, Y. (2012). lavaan: An R package for structural equation modeling. Journal of Statistical Software, 48, 1-36.

Schmitt, D. P. (2005). Sociosexuality from Argentina to Zimbabwe: A 48-nation study of sex, culture, and strategies of human mating. Behavioral and Brain Sciences, 28, 247-275.

Shackelford, T. K., Schmitt, D. P., \& Buss, D. M. (2005). Universal dimensions of human mate preferences. Personality and Individual Differences, 39, 447-458.

Soto, C. J., \& John, O. P. (2017). The next Big Five Inventory (BFI-2): Developing and assessing a hierarchical model with 15 facets to enhance bandwidth, fidelity, and predictive power. Journal of Personality and Social Psychology, 113, 117-143.

Steiger, J. H. (1990). Structural model evaluation and modification: An interval estimation approach. Multivariate Behavioral Research, 25, 173-180.

Štěrbová, Z., Bártová, K., Nováková, L. M., Varella, M. A. C., Havlíček, J., \& Valentova, J. V. (2017). Assortative mating in personality among heterosexual and male homosexual 
couples from Brazil and the Czech Republic. Personality and Individual Differences, 112, 90-96.

Strouts, P. H., Brase, G. L., \& Dillon, H. M. (2017). Personality and evolutionary strategies: The relationships between HEXACO traits, mate value, life history strategy, and sociosexuality. Personality and Individual Differences, 115, 128-132.

Souza, A. L., Conroy-Beam, D., \& Buss, D. M. (2016). Mate preferences in Brazil: Evolved desires and cultural evolution over three decades. Personality and Individual Differences, 95, 45-49.

Sugiyama, L. S. (2005). Physical attractiveness: An adaptationist perspective. In D. M. Buss (Ed.), The handbook of evolutionary psychology (pp. 292-343). Hoboken, NJ: Wiley.

Torchiano, M. (2016). effsize: Efficient effect size computation. R package version 0.6.2. https://cran.r-project.org/package $=$ effsize

Valentine, K. A., Li, N. P., Meltzer, A. L., \& Tsai, M. H. (2019). Mate preferences for warmthtrustworthiness predict romantic attraction in the early stages of mate selection and satisfaction in ongoing relationships. Personality and Social Psychology Bulletin, 0146167219855048.

Wang, S., Chen, C. C., Dai, C. L., \& Richardson, G. B. (2018). A call for, and beginner's guide to, measurement invariance testing in evolutionary psychology. Evolutionary Psychological Science, 4, 166-178.

Youyou, W., Schwartz, H. A., Stillwell, D., \& Kosinski, M. (2017). Birds of a feather do flock together: Behavior-based personality-assessment method reveals personality similarity among couples and friends. Psychological Science, 28, 276-284. 
Zhang, L., Lee, A. J., DeBruine, L. M., \& Jones, B. C. (2019). Are sex differences in preferences for physical attractiveness and good earning capacity in potential mates smaller in countries with greater gender equality?. Evolutionary Psychology, 17, 1474704919852921. 